\title{
Polipose Adenomatosa Familiar Atenuada
}

\author{
Attenuated Familial Adenomatous Polyposis
}

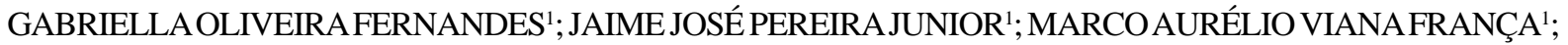 \\ JOSÉ HERMES GOMES COSTA ${ }^{1}$ \\ ${ }^{1}$ Hospital Geral de Goiânia. Goiânia - GO - Brasil.
}

\begin{abstract}
FERNANDES GO; PEREIRA JUNIOR JJ; FRANÇA MAV; COSTA JHG. Polipose Adenomatosa Familiar Atenuada. Rev bras Coloproct, 2007;27(2): 179-184.

RESUMO: A Polipose Adenomatosa Familiar Atenuada(PAFA) é uma síndrome autossômica dominante, de diagnóstico tardio, comparando-se à forma clássica da polipose adenomatosa familiar. Dentre as características da síndrome estão: a)presença de menos de 100 pólipos colorretais; b) curso brando da doença, com idade tardia do diagnóstico e do aparecimento de câncer; c)prevalência maior dos pólipos à direita do cólon; d) reto poupado de lesões, na maioria dos casos. Analisar as características clínicas, tratamento e seguimento de 13 pacientes com diagnóstico de PAFA. Dos pacientes estudados, a média de idade ao diagnóstico foi 55 anos. Cinco pacientes apresentavam história familiar de polipose e/ou neoplasia. Nove (69\%) pacientes já tinham câncer no momento do diagnóstico. A maioria dos pacientes possuía pólipos localizados no cólon direito (31\%). Do total, 06 pacientes foram submetidos à ressecção cirúrgica, com proctocolectomia ou colectomia. A média de seguimento dos pacientes foi de 26 meses. $O$ controle foi realizado através de colonoscopias e retossigmoidoscopias, de acordo com o tratamento realizado. O diagnóstico de PAFA foi feito em idade tardia em relação à forma clássica da doença, com a maioria dos pólipos localizados no cólon direito. $O$ controle endoscópico dos pacientes deve ser realizado com rigor. A colectomia com anastomose do íleo-reto é uma boa opção cirúrgica no tratamento dos pacientes, com baixa recidiva de pólipos no reto.
\end{abstract}

Descritores: Polipose familiar, polipos colonicos, adenoma

\section{INTRODUÇÃO}

A Polipose Adenomatosa Familiar Atenuada (PAFA) constitui síndrome autossômica dominante, relacionada a mutações no gene APC, porém com características distintas da Polipose Adenomatosa Familiar(PAF): a) curso brando da doença, com idade tardia no diagnóstico e no aparecimento de câncer colorretal (10-15 anos mais tarde que na PAF); b)presença de menos de 100 pólipos colorretais, na maioria dos casos; c) maior distribuição proximal dos pólipos e neoplasias no cólon; d) reto poupado das lesões, na maioria dos $\operatorname{casos}^{1,2,5,6,12,13}$.

São descritas lesões neoplásicas sincrônicas nesses pacientes e sabe-se que o reto é poupado da presença de pólipos em grande parte dos pacientes.
Por ser incomum, a incidência e freqüência da PAFA não são conhecidas, embora se estime que cerca de $10 \%$ dos pacientes apresentem o fenótipo atenuado da síndrome ${ }^{1,2}$.

O diagnóstico da doença é baseado nos achados clínicos e endoscópicos, além de testes genéticos como o Teste da Proteína Truncada e o mapeamento de DNA ${ }^{1,2,4,6,7,13}$. Pacientes com endoscopia digestiva alta (EDA) evidenciando pólipos gastro-duodenais, ou história familiar de polipose, e/ou neoplasia colorretal devem ser investigados com colonoscopia para PAFA $^{1,13}$. Assim como na polipose clássica, manifestações extra-colônicas podem estar presentes em menor escala, como tumores desmóides e hipertrofia congênita do epitélio pigmentar da retina ${ }^{1,2}$. Os pólipos gátricos e duodenais são as manifestações mais co-

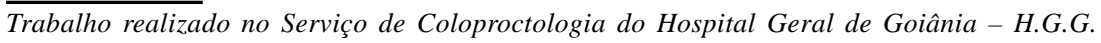

$\overline{\text { Recebido em 30/11/2006 }}$

Aceito para publicação em 24/01/2007 
muns, com relatos de transformação maligna dos mes$\operatorname{mos}^{8,9}$.

O gene APC é um supressor tumoral, agindo como barreira na sequiência adenoma-carcinoma. Dentre suas funções está a regulação intracelular de $\beta$ catenina, uma proteína associada ao fator de transcrição de células $\mathrm{T}$, relacionada à transcrição de DNA e envolvida em processos de sinalização celular que afetam a apoptose e o crescimento das células ${ }^{1,2,13}$. Mutações no APC levam à perda de sua função reguladora, com aumento de $\beta$-catenina, proliferação celular, além da transcrição de genes envolvidos no crescimento do epitélio colônico, incluindo o oncogene c-myc ${ }^{2,6,7}$. Portanto, há uma redução e perda da atividade supressora tumoral. Hoje, são descritas cerca de 34 mutações no gene APC relacionadas à PAFA, detectadas em 3 partes do gene : extremidade 5' (5 exons iniciais), exon 9 e extremidade distal $3^{\prime}$ 1,2,12,13 . Apesar de tais descobertas, cerca de $20 \%$ a $50 \%$ dos pacientes com PAF não apresentam qualquer mutação no gene APC, levando à hipótese de que genes ainda desconhecidos, fatores de crescimento, hormonais e ambientais estejam associados à fisiopatogenia da doença, resultando em características fenotípicas atenuadas ${ }^{2,6,12,13}$.

Estudos têm mostrado a presença de vários fenótipos em pacientes portadores de uma mesma mutação, com manifestações colônicas e extra-intestinais distintas, além de diferenças na progressão da doença ${ }^{1,2,6}$ A grande variedade fenotípica apresentada pelos pacientes dificulta a padronização de critérios diagnósticos para PAFA, além de casos confundidos com HNPCC e câncer colorretal (CCR) esporádi$\mathrm{co}^{4,5,13}$. Não se sabe ainda o verdadeiro risco de CCR na PAFA, sendo a indicação de colectomia profilática ainda controversa na literatura ${ }^{3,13}$. Sabe-se que em pacientes com poucos pólipos o controle endoscópico pode ser realizado periodicamente, além do uso de derivados inibidores da COX-2 (Celecoxib) na prevenção e redução dos pólipos ${ }^{5,10,11}$.

Nos casos cujo controle endoscópico seja difícil, ou ainda considerando-se o potencial maligno dos pólipos, indica-se a colectomia total com íleo-reto anastomose, ou proctocolectomia com bolsa íleo-anal ${ }^{3}$. Pacientes, cuja cirurgia preservou o reto, devem ser monitorizados com exames periódicos. Nos pacientes não operados, o seguimento é preferível através de colonoscopia, devido à localização das lesões ser mais comum no cólon direito ${ }^{1,12,13}$. O controle pode ser fei- to em períodos anuais, podendo-se utilizar técnicas de coloração que facilitem a identificação dos pólipos.

\section{OBJETIVO}

Analisar as características demográficas, manifestações colônicas e extra-colônicas, tratamento realizado e evolução clínica de 13 pacientes com PAFA, atendidos no Hospital Geral de Goiânia no período de março de 1995 a junho de 2006.

\section{PACIENTES E MÉTODOS}

Estudo retrospectivo através da análise de prontuários de 13 pacientes atendidos na referida instituição com diagnóstico clínico de PAFA. Os critérios de inclusão foram: a) presença de menos de 100 pólipos colônicos ao exame endoscópico; b) idade de diagnóstico dos pólipos e / ou câncer colorretal superior a 35 anos; c) exclusão de critérios para HNPCC. Foram analisados dados clínicos, endoscópicos, tratamento realizado e a evolução dos pacientes. Testes genéticos não foram realizados, devido à indisponibilidade dos mesmos.

\section{RESULTADOS}

Quanto ao sexo, 08(62\%) eram do sexo feminino e 5 (38\%) do sexo masculino (gráfico 1). A média de idade no momento do diagnóstico foi de 55 (37-69) anos (Tabela 1). Cinco pacientes possuíam história familiar de polipose e/ou neoplasia colorretal; dentre eles, 04 (80\%) já apresentavam CCR no momento do diagnóstico.

Os principais sintomas relatados foram: dor abdominal, sangramento retal, alteração do ritmo intestinal, anemia, nodulação anal e perda ponderal (gráfico 2). A localização dos pólipos ao exame colonoscópico foi a seguinte, em frequência: 02 pacientes no cólon esquerdo (15,38\%), 04 pacientes no cólon direito(30,77\%); 04 pacientes em todo o cólon(30,77\%) e 03 pacientes em todo o cólon e reto $(23,08 \%$ ) (gráfico 3)(Foto1). O exame histopatológico dos pólipos mostrou adenomas tubulares, adenomas vilosos e túbulo-vilosos, inclusive no mesmo paciente, com graus de atipia variados, além de pólipos hiperplásicos.

Dos 13 pacientes avaliados, 09(69\%) apresentavam câncer no momento do diagnóstico, assim distribuídos: 06(66,7\%) no cólon direito; 02 (22,2\%) no reto; e $01(11,1 \%)$ no cólon esquerdo (Foto2). 
Tabela 1 - Distribuição quanto à idade e sexo dos pacientes.

\begin{tabular}{lll}
\hline Sexo & Idade (anos) & Idade Média (anos) \\
\hline Masculino & \\
Feminino & \\
\hline
\end{tabular}

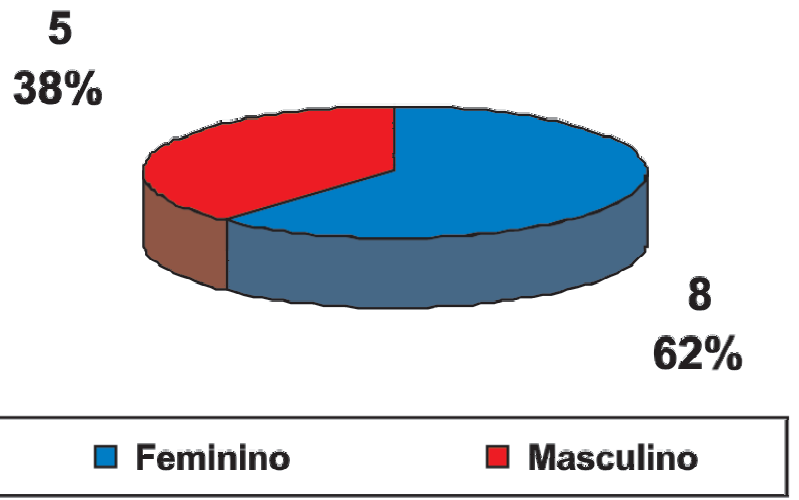

Gráfico 1 - Distribuição quanto ao sexo dos pacientes.

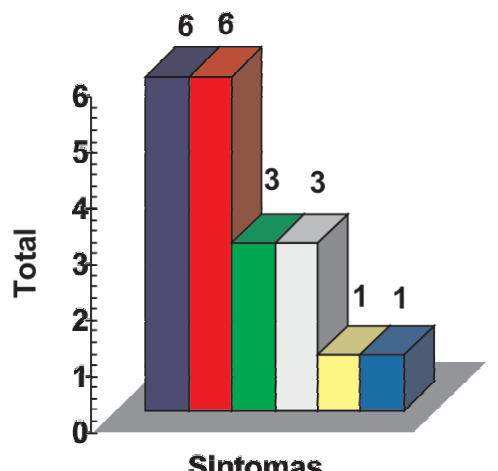

$\square$ Dor abdominal
$\square$ Sangramento
$\square$ Alteração do
ritmo intestinal
$\square$ Anemia
$\square$ Nodulação anal
$\square$ Perda ponderal

Gráfico 2 - Sintomas dos pacientes.

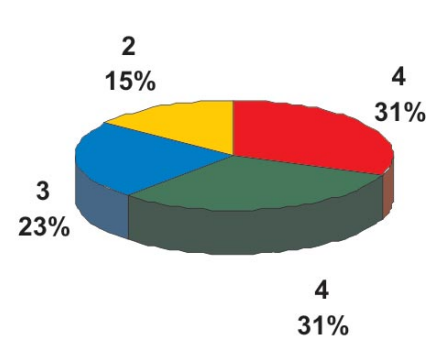

Gráfico 3 - Localização dos pólipos.

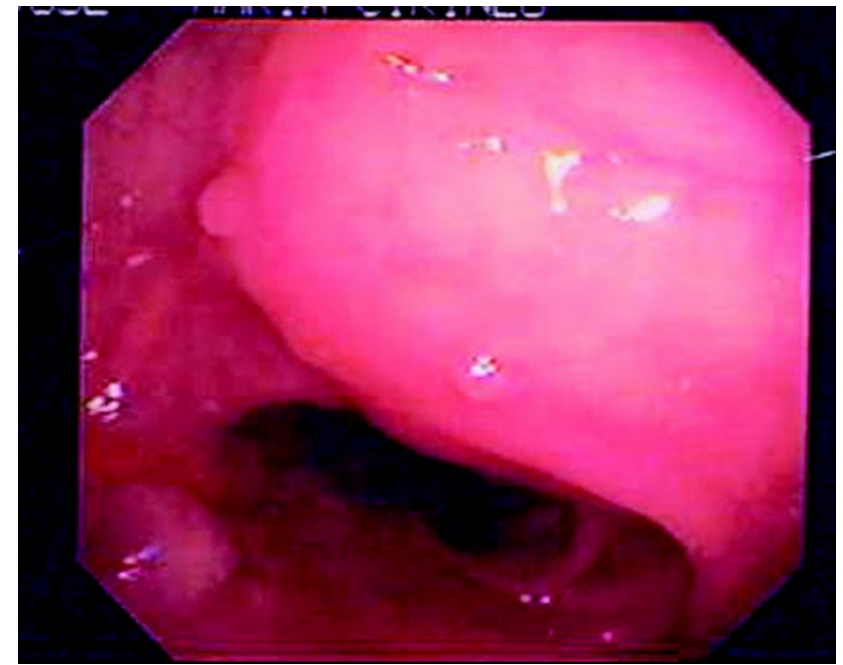

Figura 1 - Colonoscopia com pólipos no cólon direito.

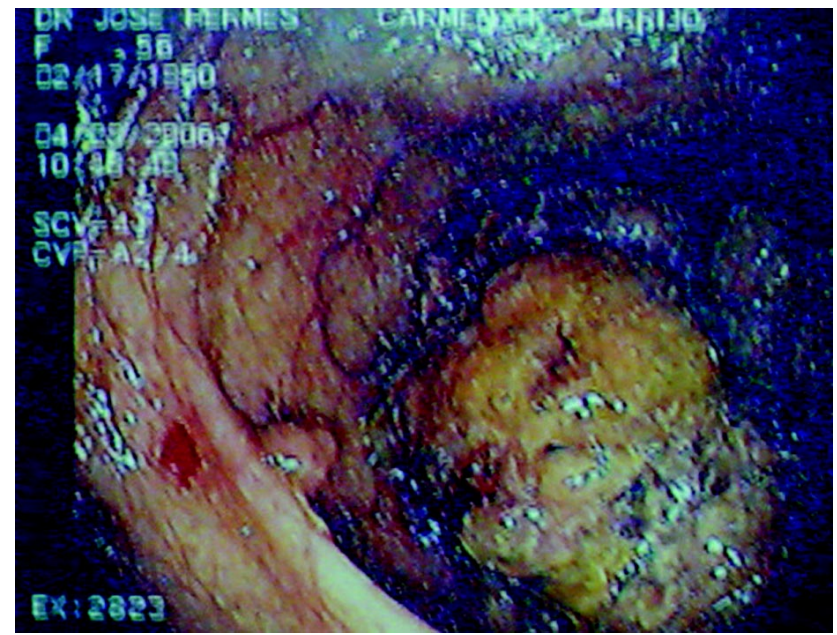

Figura 2 - Colonoscopia mostrando pólipose associada a tumor de cólon direito.

Todos os pacientes foram submetidos à EDA, evidenciando-se pólipo duodenal em apenas 01 caso, ressecado endoscopicamente, sem evidência de malignidade. Nenhum paciente apresentou outra manifestação extra-intestinal da doença.

Todos os pacientes com câncer (09) foram submetidos a tratamento cirúrgico: 06 colectomias totais e ileo-reto anastomose; 02 proctocolectomia e ileostomia definitiva; e 01 colectomia parcial (Tabela 3) (Fotos 4 e 5). Um dos pacientes com neoplasia maligna de flexura hepática do cólon foi submetido a hepatectomia parcial devido a metástase hepática e à colecistectomia. A indicação de colectomia parcial de um dos pacientes deveu-se ao quadro clínico grave, com enterorragia volumosa do tumor e coomorbidades, 
Rev bras Coloproct Abril/Junho, 2007
, 27

$\mathbf{N}^{\circ} 2$

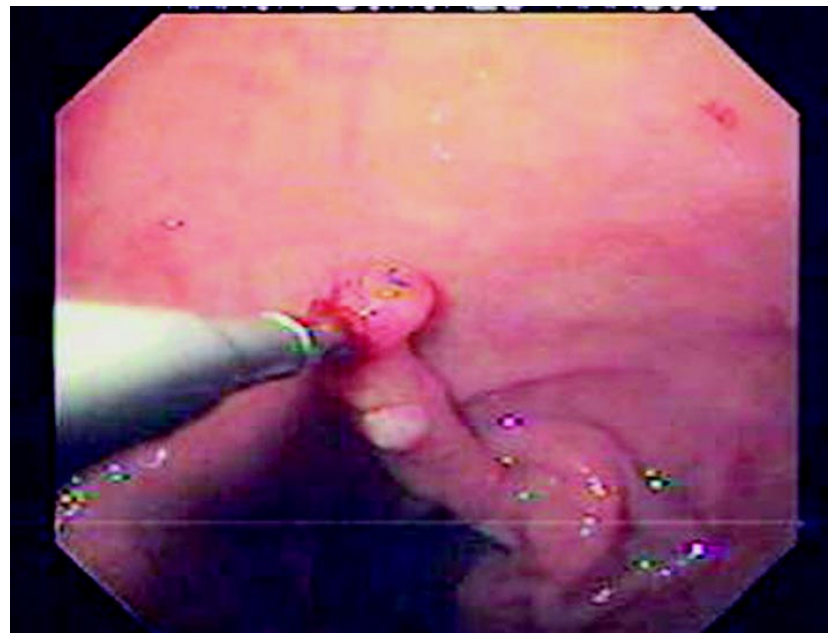

Figura 3 - EDA com presença de pólipo duodenal.

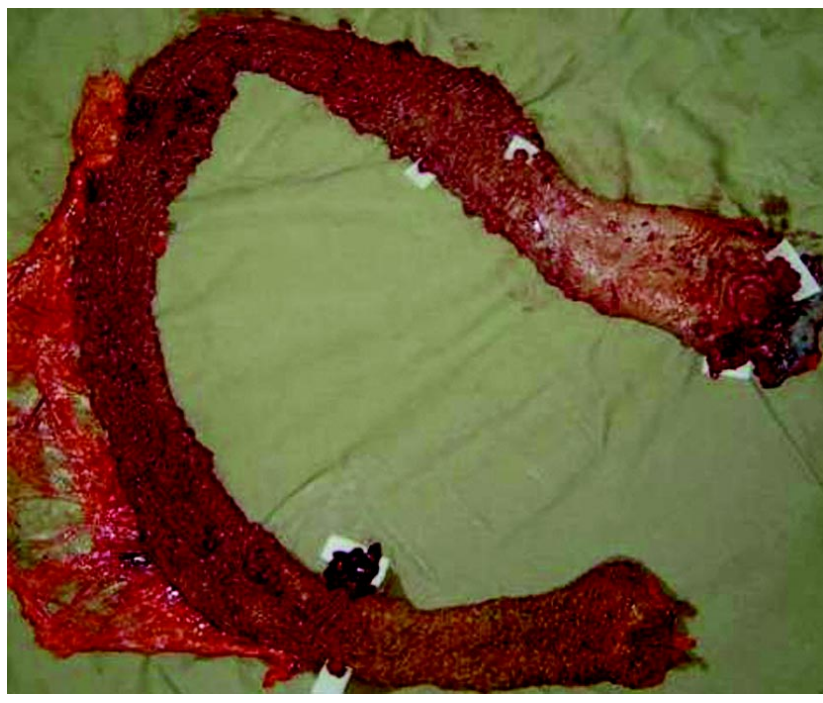

Figura 4 - Peça cirúrgica de proctocolectomia, com tumoração em reto e polipose.

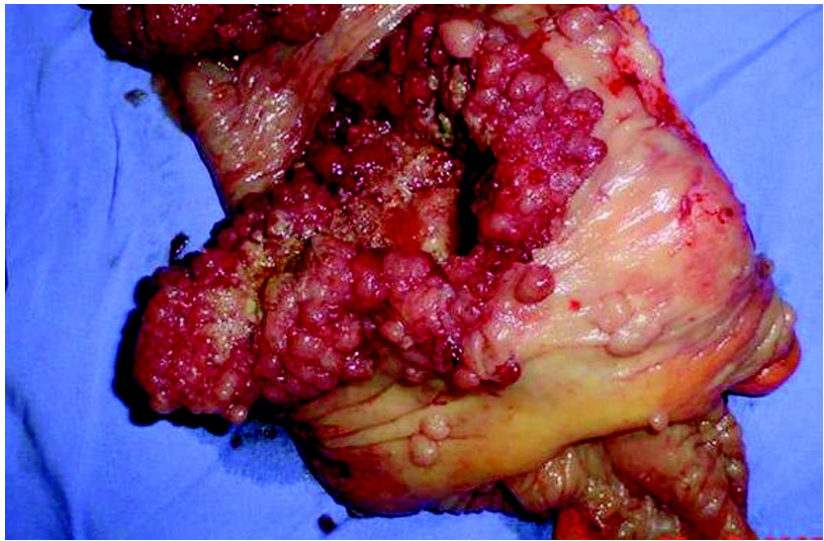

Figura 5 - Peça cirúrgica com tumoração em ceco.

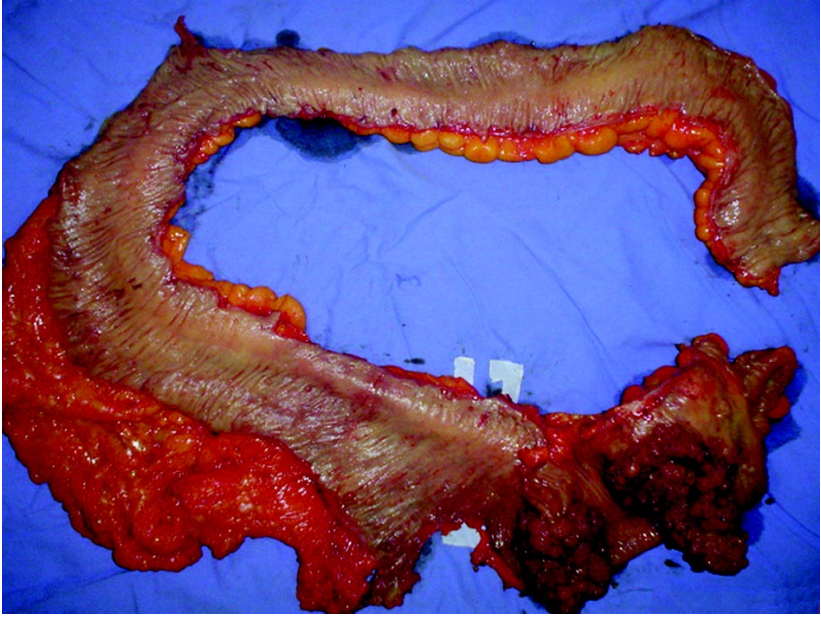

Figura 6 - Peça cirúrgica de colectomia total, com tumor sincrônico de ceco e cólon ascendente.

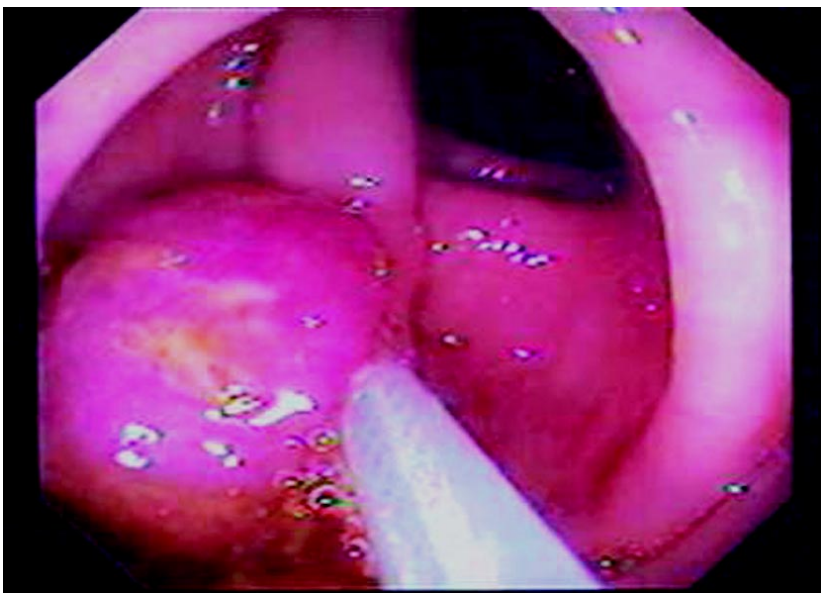

Figura 7 - Polipectomia durante controle pós-operatório em colonoscopia. 
considerando-se o risco-benefício de uma cirurgia mais agressiva. Lesões sincrônicas estavam presentes em $02(22 \%)$ pacientes, sendo 01 tumor de íleo e cólon ascendente, e 01 tumor de ceco e cólon ascendente (Foto 6).

O tempo de seguimento dos pacientes variou de 4 a 108 meses (média 26 meses). Foram realizadas retossigmoidoscopias de controle nos 05 pacientes com íleo-reto anastomose, em períodos variáveis, diagnosticando-se pólipos de reto após 04 anos em apenas um paciente. Um dos pacientes apresentou recidiva pélvica tumoral após 01 ano de cirurgia, com óbito por metástase hepática e cerebral. Os 04 pacientes não operados foram submetidos à colonoscopias seriadas, com realização de polipectomias em todos eles, não evidenciando-se transformação maligna ao exame histopatológico (Foto7). Destes, 03 pacientes fazem quimioprevenção, estando 01 paciente em uso de Celecoxib $800 \mathrm{mg} /$ dia e 02 pacientes em uso de AAS $200 \mathrm{mg} / \mathrm{dia}$, sem recidiva dos pólipos. Os familiares dos pacientes foram orientados quanto ao caráter genético da doença, no intuito de realizarem colonoscopias diagnósticas.

\section{DISCUSSÃO}

Neste estudo retrospectivo, avaliamos as características de 13 pacientes portadores de PAFA, doença autossômica dominante de diagnóstico tardio, em relação à forma clássica da PAF. A média de idade no momento do diagnóstico neste estudo foi de 55 anos, compatível com trabalhos de Soravia (58 anos) $)^{13}$ e Lamlum (54 anos) ${ }^{14}$. O diagnóstico foi baseado nas características clínicas da doença já descritas, além de história familiar de pólipos e/ou CCR. Alguns autores têm referido pacientes com PAFA com número de adenomas excedendo o critério de 100 lesões, devido à forma branda da doença e diagnóstico tardio da mesma ${ }^{15,16,17}$. A colonoscopia é o exame de escolha para o diagnóstico e screening nos pacientes, devido à localização comum dos pólipos à direita do cólon, sendo o reto poupado na maioria dos casos. $\mathrm{Na}$ nossa casuística, $31 \%$ dos pacientes apresentavam a distribuição das lesões à direita do cólon, e em $23 \%$ haviam pólipos no reto. Em série de Soravia ${ }^{13}$, em 11 famílias com 79 membros com diagnóstico de PAFA, grande parte deles apresentavam menos de 100 adenomas, com tendência a se localizarem à direita do cólon, estando o reto livre de lesões em todos os casos. A cirurgia está indicada nos pacientes com $\mathrm{CCR}$, não havendo consenso na literatura quanto à colectomia profilática.

Embora a penetrância de CCR pareça elevada, a incidência, frequiência e sobrevida dos pacientes não são conhecidas. Neste estudo, 09 dos 13 pacientes já apresentavam câncer no momento do diagnóstico, compatível com relatos de Soravia ${ }^{13}$ (24/ 79) e Spirio ${ }^{16}$ (44/90). Lynch ${ }^{18}$ preconiza colonoscopias de controle com polipectomias em pacientes com poucas lesões, e segundo Hernegger $e t a l^{12}$, a colectomia está indicada naqueles com número elevado de lesões, impossibilitados de seguimento endoscópico, ou cujas polipectomias não sejam factíveis tecnicamente. No nosso estudo houve apenas 01 óbito durante o seguimento dos pacientes, devido a câncer avançado com metástases.

Retossigmoidoscopia de controle, diferente da PAF, está indicada apenas nos pacientes com íleo-reto anastomose. Neste trabalho, dos 05 pacientes submetidos a este exame no seguimento, 01 paciente apresentou pólipo retal após 04 anos da cirurgia, confirmando a necessidade de avaliação do reto preconizada por Clark $^{19}$ e Hernegger ${ }^{13}$, mesmo com a ausência freqüente de pólipos neste segmento intestinal em casos descritos na literatura. A endoscopia digestiva alta deve fazer parte do controle desses pacientes, avaliando-se manifestações da doença no trato gastrointestinal alto.

\section{CONCLUSÃO}

$\checkmark$ O diagnóstico e a inclusão dos pacientes com PAFA, neste estudo, foram baseados em dados clínicos e endoscópicos, ocorrendo em idade tardia, com câncer colorretal presente na maioria dos pacientes.

$\checkmark$ A sintomatologia levou à realização de colonoscopia diagnóstica, com a maioria dos pólipos localizados proximal à flexura esplênica.

$\checkmark$ Tumores sincrônicos ocorreram em 02 pacientes.

$\checkmark$ Colectomia total com íleo-reto anastomose é uma boa opção cirúrgica para os pacientes com PAFA, com baixa recidiva dos pólipos no reto.

$\checkmark$ É necessário o controle endoscópico dos pacientes não operados, além de pesquisa de outras manifestações extra-colônicas da doença.

$\checkmark$ Familiares dos pacientes com diagnóstico de PAFA devem ser orientados, para que se faça o diagnóstico precoce da doença. 
ABSTRACT: Attenuated Familial Adenomatous Polyposis (AFAP) is a heritable autosomally dominant syndrome, with later diagnosis than the classical condition of Familial Adenomatous Polyposis. Amid its main features there are : a) the presence of less than 100 polyps; b) the mild course of the disease and its later diagnosis and development of colon cancer; c)the polyps are more frequent in the right colon; d)the rectum may be relatively or even totally spared. To analyze the clinical manifestations, treatment and follow-up of 13 patients with AFAP. The mean age was 55 years, five patients had positive family history of polyposis and/or colon cancer and nine $(69 \%)$ patients had already developed colonic cancer at the time of the diagnosis. Most of the patients had polyps located in the right colon. Six out of 13 patients patients had undergone surgical resection, either proctocolectomy or colectomy. The average follow-up time was $\mathbf{2 6}$ months. Periodically colonoscopy or retosigmoidoscopy were employed for follow-up evaluation, according to the previous surgical procedure. The diagnosis of AFAP was made later than the one of the classic form of the disease and most of the polyps were located in the right colon. Frequent follow-up with endoscopic examination as a follow-up is mandatory. Colectomy with ileo-rectal anastomosis is a very good option in the surgical management of these patients with low recurrence rate of rectal polyps.

Key words: familiar poluposis, colonic polyps, adnome.

\section{REFERÊNCIAS}

1. Hernegger GS, Moore HG, Guilem JG. Attenuated Familial Adenomatous Polyposis: An evolving and poorly understood entity.Dis Colon Rectum 2002; 45:127-136

2. Knudsen AL, Bisgaard ML, Bülow S. Attenuated Familial Adenomatous Polyposis (AFAP).A review of the literature. Familial Cancer 2003; 2:43-55.

3. Contessini-Avesani E, Botti F, Negri C et al. Familial adenomatous polyposis. Surgical treatment: when and how. Tech Coloproctol 2004; 8:S309-S314.

4. Half EE, Bresalier RS. Clinical management of hereditary colorectal cancer syndromes.Curr Opin Gastroenterol 2004;20:32-42.

5. Esaki M, Matsumoto T, Mizuno M et al. Effect of Sulindac treatment for attenuated familial adenomatous polyposis with a new germline APC mutation at codon 161. Dis Colon Rectum 2002;45:1397-1406.

6. Moision A-L, Järvinen H, Peltomäki.Genetic and clinical characterisation of familial adenomatous polyposis: a population based study.Gut 2002;50:845-850.

7. Neklason DW, Solomon CH, Dalton AL et al. Intron 4 mutation in APC gene results in splice and attenuated FAP phenotype.Familial Cancer 2004;3:35-40.

8. Chetty R, Salahsho S, Bapat B et al. Intraductal papillary mucinous neoplasm of the pancreas in a patient with attenuated familial adenomatous polyposis. J Clin Pathol 2005;58:97101.

9. Trimbath JD,Griffin C, Romans K et al. Attenuated familial adenomatous polyposis presenting as ampullary adenocarcinoma. Gut 2003;52:903-904.

10. Philips RKS, Wallace MH, Lynch PM et al.A randomised, double blind, placebo controlled study of celecoxib, a selective cyclooxygenase 2 inhibito, on duodenal polyposis in familial adenomatous polyposis.Gut 2002; 50:857-860.
11. Peek Jr RM. Prevention of colorectal cancer through the use of COX-2 selective inhibitors. Cancer Chemother Pharmacol 2004;54(Suppl 1):S50-S56.

12. Su L-K, Kohlmann W, Ward PA. Different familial adenomatous polyposis phenotypes resulting from deletions of the entire APC exon 15. Hum Genet 2002; 111:88-95.

13. Soravia C, Berk T, Madlensky L et al. Genotype-Phenotype correlations in attenuated adenomatous poliposis coli.Am $\mathrm{J}$ Hum Genet 1998;62:1290-1301.

14. Lamlum H, Al Tassan N, Jaeger E. Germline APC variants in patients with multiple colorectal adenomas, with evidence for the particular importance of E1317Q. Hum Mol Gen 2000;9:2215-2221.

15. The unique phenotype of the attenuated adenomatous polyposis coli syndrome. Poster/LCPG-meeting 2001; Venice, Italy.

16. Spirio L, Green J, Robertson J et al. The identical 5'splice-site acceptor mutation in five attenuated APC families from Newfounland demonstrates a founder effect. Hum Genet 1999;105:388-398.

17. van der Luijt RB, Vasen HF, Tops CM et al. APC mutation in the alternatively spliced region of exon 9 associates with late onset familial adenomatous polyposis coli patients. Hum Genet 1995;96:705-710.

18. Lynch HT, Watson P. AFAP: variety is the spice of life. Gut 1998;43:451-452.

19. Clark SK, Middleton SB, Philips RK. It is really not familial adenomatous polyposis. Dis Colon Rectum 2000;43:113.

Endereço para correspondência:

\section{GABRIELLA OLIVEIRA FERNANDES}

Endereço : Hospital Geral de Goiânia - H.G.G.

Serviço de Coloproctologia

Av: Anhanguera, No. 6379 - Setor Oeste

CEP : 74043-011 Goiânia - GO

E-mail :gabicir@ig.com.br 